\title{
COLÔNIA DE FÉRIAS: UMA EXPERIÊNCIA DE FORMAÇÃO.
}

\author{
Silvio Ricardo da Silva* \\ Poliana Bretas** \\ Carolina Drumond Porto Carreiro Caldas***
}

\begin{abstract}
RESUMO:
O presente trabalho objetivou socializar experiências educativas no campo do lazer, mais especificamente, de um projeto de extensão em uma Universidade Federal, intitulado "Colônia de Férias no Campus" e analisar seu impacto na formação de crianças, profissionais e professores. Para tal, realizamos uma pesquisa do referido projeto e cotejamos com o referencial bibliográfico que se debruça sobre a temática. Concluímos que se constitui em uma riqueza educativa para as crianças participantes, assim como para aqueles que atuam na gestão, organização e avaliação - graduandos em processo de formação, que experimentam a realidade da prática, sob um processo de acompanhamento e apoio.
\end{abstract}

Palavras-chaves: Colônia de Férias. Lazer. Formação. Educação.

As colônias de férias ao longo dos anos vêm sendo transformadas de acordo com os pressupostos e objetivos das instituições que as organizam. Isso fica explícito ao fazermos uma análise do planejamento e da execução das mesmas.

No Brasil, as colônias de férias surgem em um contexto higienista e militar onde a ordem e o patriotismo eram aspectos importantes para época. O campo da Educação Física cresce neste momento para auxiliar na formação de corpos sadios dos militares, a fim de garantir a defesa e representação da nação.

A primeira colônia de férias no Brasil iniciou na década de 1930, no Forte de São João, atual Escola de Educação Física do Exército, no Rio de Janeiro, com o objetivo de manter a ordem através da ocupação do tempo dos filhos dos militares. (STEINHILBER. 1995).

Segundo Contursi (1983), algumas colônias também tiveram o objetivo de possibilitar o contato dos participantes com a natureza, como exemplo a Colônia de Férias da Associação Cristã de Moços (ACM). Devido à urbanização, várias crianças perderam o convívio com a natureza, a $\mathrm{ACM}$, buscou resgatar os valores de respeito e cuidado com a mesma.

Alguns estudos comprovam esses ideais higienistas e militares e foram elaborados para auxiliar o trabalho neste campo. Malta (1973), em seu livro buscou sistematizar o processo de organização e execução das Colônias de Férias. Para o autor as colônias de férias eram uma possibilidade também de ascensão e incentivo para o crescimento do esporte brasileiro a partir da participação das crianças em "atividades recreativas, cívicas e desportivas, com a finalidade de estimular o gosto pelas atividades físicas, pelas noções básicas de civismo e o interesse por competições

\footnotetext{
* Professor associado da EEFFTO/UFMG e tutor do Programa de Educação Tutorial (PET) - Educação Física e Lazer

** Licenciada em Educação Física pela Universidade Federal de Minas Gerais

*** Licenciada em Educação Física pela Universidade Federal de Minas Gerais; Bolsista do Programa de Educação Tutorial (PET) - Educação Física e Lazer
} 
esportivas" (p.11). Parece que o conteúdo físico esportivo desde o surgimento das colônias foi o predominante nas programações.

Aos poucos as escolas particulares também assumiram a organização das colônias de férias que passaram a ser comercializadas com o principal objetivo de atender aos pais no período das férias ocupando o tempo de lazer dos filhos com pacotes prontos de atividades. Essa mudança ocorreu no contexto da colônia e do lazer como um todo, na medida em que o Brasil buscou com a modernização da sociedade, "uma organização progressiva do mercado de diversões". (MELLO; ALVES, 2012).

Estudos vêm questionando a organização das colônias de férias como resultado da indústria de entretenimento e ou como práticas funcionalistas. Silva (2012) confirma isso ao fazer uma proposta pedagógica de Colônias de Férias Temática que busca:

Ampliar o envolvimento, a participação e a produção cultural, pelo acesso e reconhecimento de conteúdos culturais diversificados, pela construção de novas relações sociais e, fundamentalmente, pela vivência da dimensão estética e ética que, na maioria das vezes, estão ofuscadas no cotidiano (p.13).

De acordo com a autora é possível humanizar as vivências de lazer nas colônias, a partir da mediação e não da reprodução das atividades planejadas. Essa tem sido a tentativa de um grupo do Programa de Educação Tutorial (PET) em Educação Física e Lazer da UFMG, que busca romper com as propostas instrumentalizadas das colônias e avançar no processo de organização de novas práticas educativas. Dessa forma, o presente artigo tem a intenção de socializar essa experiência educativa no campo do lazer e analisar seu impacto na formação de crianças, profissionais e professores.

O Programa de Educação Tutorial (PET) - Educação Física/Lazer foi implantado na Escola de Educação Física, Fisioterapia e Terapia Ocupacional (EEFFTO) da Universidade Federal Minas Gerais (UFMG) em 2003. De acordo com o Manual de Orientações Básicas do Programa, o PET é um programa de longo prazo que visa realizar, dentro da universidade brasileira, o modelo de indissociabilidade do ensino, pesquisa e extensão. No ano de 2009, a partir da necessidade de desenvolver intervenções baseadas em estudos acerca do lazer, o grupo iniciou o seu primeiro projeto de extensão: A Colônia de Férias no Campus (CFC) da UFMG tem como objetivo interligar as ações de ensino, pesquisa e extensão do programa, possibilitando um rico espaço de formação para os bolsistas do PET e demais graduandos da Universidade.

O projeto atende gratuitamente cerca de cento e setenta crianças, sendo fiIhos de servidores (técnico-administrativos, funcionários e terceirizados) e filhos de alunos da UFMG, com idade entre seis e treze anos, divididos em quatro turmas de acordo com a idade (6-7 anos, 8-9 anos, 10-11 anos e 12-13 anos). O processo de inscrição é realizado no campus da UFMG, na Escola de Educação Física, priori- 
zando as crianças participantes das edições anteriores, o que permite a continuidade, considerada pelo grupo como fato essencial para a formação dos sujeitos e consolidação do processo de educação para e pelo lazer, o qual, de acordo com Marcellino (2010), é fundamental para a problematização e vivência dos conteúdos culturais do lazer.

A CFC acontece no decorrer de cinco dias nos meses de janeiro e julho, no horário de oito às dezessete horas e possui uma equipe de animadores culturais composta por trinta alunos de graduação, sendo doze bolsistas do PET e dezoito alunos do curso de Educação Física e cursos que se relacionem com o campo do Lazer, como o curso de Turismo, Belas Artes, Música, entre outros. Para a formação dos animadores, são realizados encontros com o objetivo de capacitá-los a uma intervenção qualificada, baseada nos conteúdos culturais do lazer (físico-esportivo, manual, artístico, turístico, intelectual e social) e na relação entre animadores e público. Ao final da programação de cada dia, são realizadas reuniões de avaliação com todos os animadores, onde o objetivo é relatar os acontecimentos e discuti-los, a fim de proporcionar sugestões e críticas. Além disso, o projeto conta com o apoio de alguns órgãos da Universidade, como a Escola de Educação Física, Fisioterapia e Terapia Ocupacional (EEFFTO), a Pró-Reitoria de Extensão (PROEX), o Departamento de Serviços Gerais (DSG) da UFMG e a Fundação Universitária Mendes Pimentel (FUMP).

Até o presente momento ${ }^{1}$ foram realizadas seis edições do projeto, sendo as quatro últimas temáticas, a saber: III CFC - "Eu amo minhas férias em BH Radicalmente"; IV CFC - "Minhas férias em 3D"; V CFC - "Uma viagem em cinco dias"; e VI CFC - "Se essa rua fosse minha...". Segundo Silva (2012), a Colônia de Férias Temática (CFT) pode assumir vários significados, mas interessa-nos, em especial, a reflexão a respeito de como humanizar a vivência nessas programações, admitindo como responsabilidade central do animador cultural a mediação e não reprodução de atividades em que, na maioria das vezes, ele próprio é o centro das atenções. Dessa forma, o grupo entende que a escolha de um tema é essencial para a elaboração de atividades contextualizadas, nas quais todos os integrantes participem da construção, partindo de investigações e questionamentos acerca da realidade em que as crianças estão inseridas, de forma a problematizá-la.

De acordo com Silva (2012):

(...) A Colônia de Férias Temática não responde apenas à perspectiva de ser vista como produto a ser consumido nas férias, mas ganha outras dimensões, passando a ser entendida como processo, qualificado pelas relações entre os significados (conteúdos) e os significantes (formas de expressão dos mesmos), da contínua convivência e comunicação entre os sujeitos (p.25).

\footnotetext{
${ }^{1}$ Dezembro de 2012.
} 
A partir de estudos realizados dentro do grupo PET, principalmente a respeito das Colônias de Férias Temáticas (CFT's), assim como de avaliações sobre as experiências anteriores, na terceira edição da CFC foi estabelecido um tema norteador para as turmas de diferentes faixas etárias basearem a sua programação.

O tema da terceira CFC, que aconteceu em Julho de 2009, denominou-se "Eu amo minhas férias radicalmente em $\mathrm{BH}$ " e foi fruto de uma discussão realizada pelos integrantes do PET, na qual foi diagnosticado que em Belo Horizonte existem variados espaços públicos e possibilidades de vivências de lazer, principalmente no período de férias. No entanto, notou-se que poucos espaços eram conhecidos pelas crianças e que a apropriação dos mesmos poderia se dar de diferentes formas. Com isso, o objetivo do tema foi explorar os espaços públicos de Belo Horizonte, estimulando nas crianças a apropriação e reapropriação dos espaços, das brincadeiras, e das relações estabelecidas. A partir do tema central, as turmas de diferentes faixas etárias estabeleceram subtemas que colaboraram com o melhor desenvolvimento da programação e da elaboração de sentidos e significados pelos sujeitos envolvidos na intervenção. Assim, na turma de oito e nove anos de idade, os animadores construíram o subtema "Brincadeiras de rua", optando por resgatar as brincadeiras de rua como forma de estímulo ao imaginário das crianças, pois estas, nas várias possibilidades de diálogo com os espaços, os diferentes materiais, os brinquedos, as brincadeiras, nas suas fantasias de faz de conta, materializam uma riqueza educativa que talvez nenhuma outra relação ou instituição possibilite (DEBORTOLLI, 2002).

Para provocar a imaginação das crianças, a turma adotou duas personagens que as acompanharam durante toda a colônia: a galinha "Gertrudes Josefina" e a boneca de pano "Terezinha". Além disso, foi passado o filme "O menino maluquinho", baseado no livro de Ziraldo e dirigido por Helvécio Ratton, com o intuito de apresentar diferentes brincadeiras que seriam, posteriormente, vivenciadas por elas, como por exemplo: o bente altas, o carrinho de rolimã, o rouba bandeira, o pegapega, entre outros. Utilizando alguns espaços públicos de $\mathrm{BH}$, tais como o Parque das Mangabeiras e o Parque Ecológico da Pampulha, a turma se propôs a se apropriar dos mesmos através de brincadeiras de rua, dialogando com as crianças e com a sua capacidade imaginativa.

Tendo em vista que os temas e conteúdos explorados nas três colônias de férias anteriores buscaram resgatar antigos jogos, brinquedos e brincadeiras, devido ao fato de que a infância e a adolescência têm sofrido fortes impactos socioculturais como resultado do acelerado processo industrial e tecnológico, o PET enxergou a necessidade de problematizar esse fato, reconhecendo que a sociedade vem se transformando e as novas gerações são frutos dessa transformação. Assim, o grupo debateu sobre a importância da virtualidade como conteúdo cultural do lazer, da reflexão crítica em relação à mesma e sobre a carência de estudos a respeito do processo de formação de animadores culturais e educadores da área.

Sendo assim, a quarta CFC aconteceu em Janeiro de 2011 e teve como tema geral "Minhas férias em 3D". O objetivo foi proporcionar atividades que dialogassem 
com o virtual, por meio da reapropriação de brincadeiras, jogos e personagens virtuais, instigando nas crianças e adolescentes a imaginação e a capacidade de reapropriação das mídias contemporâneas.

As imagens da fantasia não aparecem prontas, elas se constroem a partir de elementos da realidade que ao serem reelaborados em nosso pensamento são convertidos em frutos da imaginação. Esse fruto pode se materializar e voltar-se para a realidade sendo capaz de até mesmo modificá-la. Esse raciocínio compõe o que Vygotsky (2007, p. 25) denomina de "círculo da atividade criadora da imaginação humana".

A partir de três reuniões de formação, sendo que em uma delas houve a presença e fala de uma estudiosa da temática, e de leituras de alguns textos sobre virtualidade e educação, as turmas das diferentes faixas etárias alcançaram maior base teórica para desenvolver e estruturar o planejamento das atividades. Como exemplo, na turma de oito e nove anos de idade, os animadores culturais desenvolveram o subtema "Colônia's Game”, o qual teve o objetivo de dialogar com os jogos eletrônicos presentes no cotidiano das crianças, possibilitando que elas problematizassem os mesmos e se apropriassem deles para construir novas possibilidades de jogos e desafios. Para isso, os animadores construíram uma maquete de videogame gigante, a qual representou o passaporte para as crianças enfrentarem os desafios propostos a cada dia. Esses desafios se apresentaram em um formato de jogos eletrônicos, os quais eram vivenciados utilizando o corpo e o movimento, sendo que ao final de cada dia as crianças deveriam derrotar um "chefão" e só assim poderiam passar para a outra fase do jogo, que seria o próximo dia de colônia. Essa estratégia, utilizada nos jogos virtuais, envolveu as crianças na construção das brincadeiras e permitiu que as mesmas dialogassem com os jogos eletrônicos e ampliassem as possibilidades de apropriação dos mesmos.

Partindo das colônias anteriores e de reflexões a respeito de acontecimentos, atitudes e representações diagnosticadas, o PET chegou ao tema da quinta CFC: "Uma viagem em cinco dias". De acordo com Marcellino (2010), ao valorizar no lazer as possibilidades de descanso e desenvolvimento social e individual, abrimos oportunidades para ressignificar o cotidiano. O tema "Uma Viagem em 5 Dias" teve como objetivo possibilitar um ambiente em que as crianças pudessem vivenciar novas experiências, a partir de viagens em diferentes âmbitos, seja geográfica, física, intelectual, temporal, imaginária ou cultural.

Além disso, contamos com a colaboração do professor Dr. José Alfredo Debortolli, o qual nos auxiliou na discussão sobre cultura e infância, e também com a leitura de outros textos auxiliadores. De acordo com Debortolli (2002), a criança deve ter um tempo que Ihe possibilite vivenciar cada momento em seu significado, e por outro lado, o educador deve saber através de que estratégias, prepará-la para o momento seguinte, colocando-a em contato com novas vivências. A partir do diálogo com diferentes culturas, torna-se possível problematizar juntamente com as crianças aspectos sociais, geográficos, físicos, temporais e intelectuais. Com isso, os anima- 
dores culturais da turma de dez e onze anos de idade estabeleceram o subtema "Uma viagem multidimensional" e buscaram realizar, a cada dia, uma viagem diferente.

Como exemplo, em um dia da colônia foi feita uma viagem paralímpica, na qual as crianças vivenciaram diferentes modalidades adaptadas, tais como o futebol para cegos e o basquete para cadeirantes. Essa viagem caracterizou uma passagem cultural, social, física e intelectual, no sentido de experimentar o mesmo jogo em um diferente formato e a partir disso conhecer outra possibilidade de manifestação esportiva, reconhecendo novas capacidades de realização dos esportes. Já em outro dia de colônia, foi realizada uma viagem para um sítio localizado na região metropolitana de Belo Horizonte. Nesse sítio, as crianças experimentaram diversas vivências da roça, tais como: tirar leite da vaca, cuidar das galinhas, andar pelo mato, nadar na cachoeira, entre outros. Além de uma viagem geográfica, foi realizada uma viagem cultural, pois as crianças se envolveram com um espaço diferente e cada uma se relacionou com o mesmo de uma forma distinta.

A sexta CFC, realizada em Janeiro de 2012, teve como tema geral "Se essa rua fosse minha", e seu objetivo foi problematizar e refletir sobre uma infância globalizada que está cercada dos meios de comunicação, atraída pelo consumismo e muitas vezes vítima da rotina do adulto. Concordando com Debortolli (2002) que não existe uma criança universal e sim crianças com existências plurais e que a ludicidade é a capacidade de brincar com a realidade, o PET propôs uma semana que instigasse as crianças a serem produtoras de cultura e detentoras de desejos e sonhos. Para isso, o grupo explorou o universo dos jogos, das brincadeiras e do faz de conta e proporcionou um ambiente de criação, criticidade, questionamento e conhecimento.

Os animadores culturais da turma de doze e treze anos de idade estabeleceram o subtema "A rua no meu tempo" e tiveram como objetivo principal problematizar a sociedade moderna, possibilitando as crianças o contato com as ruas de Belo Horizonte e a autonomia em tomar as suas próprias decisões durante a colônia, principalmente em relação às brincadeiras realizadas. Destaca-se o dia em que a turma foi a Praça da Estação, espaço público da cidade, sendo que as crianças tiveram que pesquisar os ônibus que deveriam pegar para chegarem ao local e tiveram a experiência de pegar um ônibus, pagando a passagem e passando pela roleta. Além disso, as mesmas andaram pelo centro da cidade, passando pelo Parque Municipal e depois chegando a Praça da Liberdade. Ou seja, em apenas um dia as crianças visitaram três espaços públicos da cidade e tiveram a autonomia de descobrir como chegar aos mesmos e se apropriar dos locais a sua maneira.

A partir das ilustrações acima, foi possível perceber que, como ferramenta para o processo de formação dos animadores, o grupo conta com a participação de um professor da Universidade que apresente relações acadêmicas com a temática estabelecida para fomentar uma discussão e colaborar com o processo criativo de planejamento das atividades e da intervenção. Além disso, outros métodos são utiliza- 
dos, tais como: a leitura de textos relacionados com lazer, animação cultural, colônia de férias e a temática estabelecida; a realização de reuniões coletivas que permitam a chamada "chuva de ideias", na qual os animadores têm a possibilidade de pensar estratégias para desenvolver a temática; e o debate coletivo sobre os textos lidos. Por fim, cada grupo de animadores, divididos nas turmas de diferentes faixas etárias, realiza reuniões semanais para a elaboração do seu planejamento de atividades para os cinco dias de intervenção, o qual deve estar pronto em um prazo previamente estabelecido.

Como escrito anteriormente, o planejamento das atividades a serem realizadas durante a intervenção é feito coletivamente entre os animadores das diferentes turmas, contribuindo de forma significativa para a qualificação do mesmo. $O$ fato de todos os animadores terem conhecimento das atividades e dos pressupostos teóricos estabelecidos para as mesmas favorece a construção de sentidos e significados por todos os sujeitos envolvidos, na medida em que a troca de experiências permite a (re) apropriação das brincadeiras, dos espaços e das vivências culturais programadas.

Nesse sentido, após as seis colônias de férias já realizadas pelo grupo PET, juntamente com as discussões teóricas pautadas nas experiências dos sujeitos como animadores culturais e nas avaliações já realizadas sobre todo o processo de organização, planejamento e execução do projeto, torna-se possível dialogar com alguns autores da área de educação, lazer, cultura e sociedade sobre o impacto que as vivências culturais no âmbito do lazer podem ter nas crianças e adolescentes participantes. Dessa forma, é importante destacar, de acordo com Debortolli, Linhales e Vago (2002), que as crianças não podem ser consideradas um mero campo de projeções - uma "massa amorfa", um ser de natureza "ideal" e "padronizada", um projeto de "vir-a-ser" linear, ordenado, hierarquizado. É preciso incorporar as crianças como sujeitos coletivos que devem participar de sua construção cultural e política. É a partir dessa concepção que o lazer pode ser considerado um tempo-espaço de apropriação diversificada e de consequente ampliação cultural por meio das práticas vivenciadas, sejam praticadas no sentido literal da palavra ou fruídas, de acordo com o desejo do sujeito.

Seguindo o pensamento de Debortoli (2002), é fácil identificar a riqueza e a diversidade da existência cultural dos seres humanos, de suas infinitas possibilidades de interação e manifestações culturais e sociais. Aliás, na brincadeira há a partiIha de significados que marcam cada existência social e também há a atribuição de novos significados, que podem, até mesmo, ressignificar os objetos. Por isso, o animador cultural, enquanto mediador da intervenção precisa pensar quais elementos estão presentes nas relações que estão sendo estabelecidas ao longo das brincadeiras, assim como quais valores, conceitos, preconceitos e significados estão sendo partilhados com as crianças. 
Todas essas experiências aqui narradas trouxeram também a possibilidade da imaginação mediada por aquilo que Girardello (2011), entende como essencial: a arte, o tempo, a natureza, a mediação adulta e a narrativa.

Conclui-se dessa forma que o projeto de extensão "Colônia de Férias no Campus" constitui-se em uma riqueza educativa para as crianças e adolescentes participantes, assim como para aqueles, que atuam na gestão, organização e avaliação - graduandos em processo de formação, que podem experimentar a realidade da prática, sob um processo de acompanhamento e apoio.

\section{REFERÊNCIAS BIBLIOGRÁFICAS}

CONTURSI, Ernani B. Curso de Colônia de Férias. Revista Sprint, jan-fev/1983, p.33-40.

. Experiências com o Lazer em Colônias de Férias Temáticas. $1^{\mathrm{a}}$ edição. Campinas - SP: Editora Alinea, 2012. 13 p.

DEBORTOLI, José Alfredo Oliveira; LINHALES, Meily Assbú; VAGO, Tarcísio Mauro. Infância e conhecimento escolar: princípios para a construção de uma Educação Física "para" e "com" as crianças. Revista Pensar a Prática, Goiânia: Ed. UFG, v. 5, p. 92-105, jul./jun. 2001 - 2002.

DEBORTOLI, José Alfredo Oliveira. As crianças e a brincadeira. In: CARVALHO, Alysson; SALLES Fátima; GUIMARÃES Marília. (Orgs.). Desenvolvimento e Aprendizagem. Belo Horizonte: Editora UFMG; Proex - UFMG, 2002. p. 72-88.

GIRARDELLO, Gilka. Imaginação; arte e ciência na infância. Pró-Posições, Campinas, v.22, n.2 (65), p.75-92, maio/ago., 2011.

MALTA, Wanceslau. Colônia de Férias Organização e Execução. $1^{a}$ edição. São Cristóvão - RJ. Editora Artenova s.a, 1973. 11 p.

MARCELLINO, N.C. Lazer e educação. Campinas: Papirus, 2010.

MELO, Victor Andrade de; ALVES JR. Edmundo de Drummond Alves. Introdução ao Lazer. 2ํㅡㄹ Edção. Barueri -SP: Editrora Manole Ltda, 2012. 
Programa de Educação Tutorial. Manual de Orientações Básicas - Manual de Orientações Básicas - $\quad$ PET/2006. Disponível em: $<$ http://portal.mec.gov.br/index.php?option=com content\&view=article\&id=12228\&lte $\underline{\mathrm{mid}=486}>$ Acesso em setembro 2012

SILVA, Débora Alice Machado. Colônia de Férias Temática: fundamentando a ação a partir das contribuições de Paulo Freire. 2008. Tese (Mestrado) - Faculdade de Ciências da Saúde, Universidade Metodista de Piracicaba, Piracicaba, 2008.

Experiências com o Lazer em Colônias de Férias Temáticas. $1^{a}$ edição. Campinas - SP: Editora Alinea, 2012. 164 p.

STEINHILBER, Jorge. Colônia de Férias - organização e administração. Rio de Janeiro, Editora Sprint, 1995.

VYGOTSKY, Lev Semenovitch. La imaginación y el arte arte em la infância. 8 ed. Madrid: Ediciones Akal, 2007.

\section{SUMMER CAMP: AN EDUCATIONAL EXPERIENCE}

\section{ABSTRACT:}

The current work had the purpose to socialize educational experiences in the field-work of leisure, specifically, in a Federal University Extension Project, titled as "Summer Camps at University Campus" and analise its consequences on the pedagogic training of professionals and teachers and also the kids social formation. To play its role, we did a research study about that Project and collated to the bibliographical reference that supports that thematic. We come to a conclusion that this summer camp experiences are educacional riches for the participating children, as well as for the ones who work in managing, organizing and evaluating - undergraduates in process of academic training who can experiment the theory applied in practice under monitoring, assistence and support.

Keywords: Summer Camp. Leisure. Formation. Education. 
El presente trabajo tiene como objetivo socializar experiencias educativas en el campo del ocio, más específicamente, de un proyecto de extensión en la Universidad Federal, titulado "Colonia de vacaciones en el campus" y analizar su impacto en la formación de niños, profesionales y profesores. Para tal, realizamos una investigación del referido proyecto y cortejamos con el referencial biográfico disponible sobre la temática. Concluimos que constituye una riqueza educativa para los niños participantes, así como para aquellos que actúan en la gestión, organización y evaluación - alumnos de grado en proceso de formación, que experimentán la realidad de la práctica, sobre un proceso de acompañamiento y apoyo.

Palabras claves: Colonia de Vacaciones. Ocio. Formación. Educación.

Endereço para correspondência: prof.srs@gmail.com 